\title{
Prevalence of disabling hearing loss in the elderly
}

\section{Letícia Raquel Baraky Vasconcelos, Paula Ferraz Rodrigues, Paula Liziero Tavares and Audryo Oliveira Nogueira*}

Federal University of Juiz de Fora, Brazil

\section{Abstract}

Introduction: Disabling hearing loss refers to hearing thresholds superior than $40 \mathrm{~dB}$ in the better ear in the adults. The main cause of hearing loss in the elderly is the age-related hearing loss, also called presbycusis. This type of hearing impairment occurs as individuals grow older and is usually sensorineural hearing disorder greater for high-pitched sounds and affects both ears equally. It is estimated that $\mathbf{4 6 6}$ million people worldwide have disabling hearing loss, one third of which are over 65 years old.

Objective: To analyze the prevalence of disabling hearing loss in the elderly of Juiz de Fora. Methods: Cross-sectional study with 122 patients. Pure tone audiometry was performed after meticulous physical examination of the external ear.

Results: Out of 122 older adults, 85 (69,6\%) presented disabling hearing loss.

Conclusion: Hearing loss, specially disabling hearing loss, is a frequent condition in the elderly and has a big impact on their quality of life. For that it should be promptly diagnosed so treatment can be initiated.

\section{More Information}

*Address for Correspondence: Audryo Oliveira Nogueira, Federal University of Juiz de Fora, Brazil; Email: audryonogueira@gmail.com

Submitted: 11 September 2019

Approved: 18 September 2019

Published: 19 September 2019

How to cite this article: Vasconcelos LRB, Rodrigues PF, Tavares PL, Nogueira AO. Prevalence of disabling hearing loss in the elderly. Adv Treat ENT Disord. 2019; 3: 012-013.

DOI: dx.doi.org/10.29328/journal.ated. 1001008

Copyright: () 2019 Vasconcelos LRB, et al. This is an open access article distributed under the Creative Commons Attribution License, which permits unrestricted use, distribution, and reproduction in any medium, provided the original work is properly cited

Check for updates

\section{Introduction}

Hearing loss refers to reduced ability to hear and is defined as hearing thresholds of $25 \mathrm{~dB}$ or worse. According to the World Health Organization, hearing loss is classified as mild, moderate, severe or profound if hearing thresholds are above, respectively, $25 \mathrm{~dB}, 40 \mathrm{~dB}, 70 \mathrm{~dB}$ and $90 \mathrm{~dB}$, but also as sensorineural, conductive or mixed [1,2]. The main cause of hearing loss in the elderly is the age-related hearing loss, also called presbycusis. This type of hearing impairment occurs as individuals grow older and is usually sensorineural hearing disorder greater for high-pitched sounds and affects both ears equally. It is mainly caused by age-related changes in the inner ear, such as loss of inner hair cells and decreased blood supply, but yet the cumulative effect of chronic and repeated noise exposure can be associated. An important detail is that, because the process is gradual, people who have age-related hearing loss may not realize their capability of hearing is diminished [2-5]. Disabling hearing loss, in its tun, is characterized by hearing thresholds superior than 40 $\mathrm{dB}$ in the better ear in the adults (Site WHO). It is estimated that 466 million people worldwide - over 5\% the world's population - have disabling hearing loss. One third of these people are over 65 years old (Site WHO). In Juiz de Fora, the prevalence of disabling hearing loss in the general population was $5,2 \%$ in 2011 [6]. Hearing impairment brings an enormous impact on the individual's ability to communicate with others. Such difficulty can cause loneliness, isolation, frustration, depression and dementia, besides of enormous economic impact $[7,8]$. The objective of this study was to analyze the prevalence of disabling hearing loss in the elderly of Juiz de Fora.

\section{Methods}

This is a cross-sectional descriptive study, whose prevalence measure was estimated in relation to the number of individuals with disabling hearing loss compared to the total number of individuals investigated, according to age group over 60 years old. The research was approved by Research Ethics Committee of UFJF Committee and was performed at a reference center for elderly patients. All the patients who were recruited signed the Free Informed Consent Form. The sample of this study was comprised of only one group: 122 individuals over 60 years old who agreed to participate on the research. A data collection questionnaire was applied, based on the WHO model (1999) with modifications, including the inclusion of other variables of interest. Pure tone audiometry 
was performed in 122 patients after meticulous physical examination of the external ear. Data was collected and compiled. A simple math equation was performed to achieve the prevalence of disabling hearing loss in the sample studied.

\section{Results}

Out of 122 older adults, 85 (69,6\%) presented disabling hearing loss.

\section{Discussion}

The prevalence of disabling hearing loss is this sample was bigger than in the general population of elderly people. This may be explained by the fact that all the patients had other health problems- reason why they attend to a reference center.

\section{Conclusion}

Hearing loss, specially disabling hearing loss, is a frequent condition in the elderly and has a big impact on their quality of life. For that it should be promptly diagnosed so treatment can be initiated.

\section{References}

1. Word Health Organization. Deafness and Hearing Loss. 2019.

2. Hear-lt. What is Hearing Loss? 2019.

3. National Institute on Deafness and Other Communication Disorders. Noise-Induced Hearing Disorders. 2019.

4. Cunningham LL, Tucci DL. Hearing Loss in Adults. N Engl J Med. 2017; 377: 2465-2473.

PubMed: https://www.ncbi.nlm.nih.gov/pubmed/29262274

5. Rosenhall ULF. The two faces of presbyacusis: hearing impairment and psychosocial consequences. Int J Audiol. 2002; 41: 125-135. PubMed: https://www.ncbi.nlm.nih.gov/pubmed/12212858

6. Baraky LR. Prevalência de surdez incapacitante no município de Juiz de Fora, Minas Gerais, Brasil. 2011.

7. Brewster KK. Age-Related Hearing Loss and Its Association with Depression in Later Life. Am J Geriatr Psychiatry. 2018; 26, 788-796. PubMed: https://www.ncbi.nlm.nih.gov/pubmed/29752060

8. Loughrey DG, Kelly ME, Kelley GA. Association of age-related hearing loss with cognitive function, cognitive impairment, and dementia: a systematic review and meta- analysis. JAMA Otolaryngol Head Neck Surg. 2018; 144: 115-126.

PubMed: https://www.ncbi.nlm.nih.gov/pubmed/29222544 